\title{
Diferença sexual, psicanálise e contemporaneidade: novos dispositivos e apostas teóricas*1
}

\section{Sexual difference, psychoanalysis and contemporaneity: new apparatus and theoretical approaches}

Mariana Pombo*1

Este artigo pretende revisar a categoria de diferença sexual na teoria psicanalítica, levando em conta a crítica das teorias feminista e queer à psicanálise, e as mudanças no campo da sexualidade que marcam a atualidade. Para isso, são exploradas novas apostas teóricas de autores contemporâneos no sentido da positivação das diferenças: gozo suplementar (J. Sáez e F. Fajnwaks), lógica do limiar (J. Gondar), vizinhança dos sexos (S. Prokhoris) e feminilidade (J. Birman e M. Arán).

Palavras-chave: Psicanálise, diferença sexual, contemporaneidade, diferenças

*1 Este trabalho é derivado da tese de doutorado da autora em Teoria Psicanalítica pela Universidade Federal do Rio de Janeiro - UFRJ, orientada por Joel Birman e defendida nessa instituição em julho de 2016.

*2 Universidade Federal do Rio de Janeiro - UFRJ (Rio de Janeiro, RJ, Brasil). 


\section{Introdução}

A teoria feminista, e mais recentemente a teoria queer, têm endereçado críticas importantes à psicanálise, sobretudo a Freud e a Lacan. A centralidade do falo, as diferenças entre o complexo de Édipo no homem e na mulher a partir de sua articulação com o complexo de castração, as noções de angústia de castração e inveja do pênis, a maternidade como condição para a feminilidade: estes são alguns dos temas alvos de crítica, temas que apontam para uma leitura da diferença sexual marcada pelo binarismo, a hierarquia entre os sexos e a referência ao falo e à anatomia.

As críticas ganham força no cenário contemporâneo, que, por ser marcado por mudanças significativas no campo da sexualidade e da família, denuncia os limites dessa leitura da diferença sexual e indica a necessidade de sua problematização e reformulação. É, portanto, dessa necessidade de revisão da categoria de diferença sexual na teoria psicanalítica que este artigo parte. Revisão fundamental, inclusive, para que a clínica atual possa acolher pacientes cujos corpos, sexualidades, escolhas amorosas e famílias não se "enquadram" nos referenciais teóricos clássicos da psicanálise.

E, se essa revisão é possível, é porque se interpreta aqui a diferença sexual do ponto de vista histórico, como um dispositivo, no sentido usado por Michel Foucault (1976/2013) em História da Sexualidade $1-A$ vontade de saber. Isso significa defender que a leitura da diferença entre os sexos feita por Freud e reforçada por Lacan encontrou suas condições de possibilidade de emergência em determinada época histórica (a modernidade) e que hoje, com as transformações na cultura, outras leituras são possíveis e devem ser exploradas se quisermos ter uma escuta clínica acolhedora e singular.

Quando, ao contrário, se faz um uso a-histórico (e mesmo estruturalista) da categoria de diferença sexual, tida como verdade universal da qual tudo depende — o bom exercício da função 


\section{ARTIGOS}

paterna, o Édipo, o acesso à ordem simbólica, a emergência do sujeito e da capacidade de desejar por conta própria —, a única posição possível diante do que surge de novo no campo da sexualidade e da família é a interpretação negativa, pelo viés do declínio, do indesejável. A consequência então de se recorrer à imutabilidade e à a-historicidade do conceito é que certas subjetividades, sexualidades, corpos e famílias (transexuais, queer, intersexo, famílias mono, homo ou pluriparentais, por exemplo) são excluídos do campo da inteligibilidade, afetando certamente o modo como serão tratados na cultura e, inclusive e sobretudo, na clínica.

Partindo, assim, de uma interpretação histórica da diferença sexual e ainda da tentativa de dar conta da complexidade e da diversidade das subjetividades e sexualidades na atualidade, o artigo que se segue irá se debruçar sobre novas apostas teóricas de autores que repensam o conceito de diferença sexual no sentido da positivação e do acolhimento das diferenças.

$\mathrm{O}$ texto começa com um resumo crítico da leitura da diferença entre os sexos em Freud e em Lacan. Em seguida, veremos as ideias dos autores Javier Sáez e Fabian Fajnwaks, que defendem o recurso a conceitos mais tardios da obra de Lacan - fórmulas da sexuação, gozo suplementar - , como possibilidade de pensar a diferença sexual hoje de maneira subversiva. Exploraremos suas potencialidades, mas também seus impasses, na medida em que parecem manter a a-historicidade e a condição de estrutura da nova construção teórica de que se apropriam, além da referência ao falo e o binarismo. Por fim, serão expostas as propostas dos psicanalistas Jô Gondar, Sabine Prokhoris, Joel Birman e Márcia Arán de novos dispositivos e linguagens para pensar as sexualidades sem enquadramento binário ou referência ao falo.

\section{Diferença sexual em Freud e Lacan}

Em Freud, a representação da diferença sexual se estabelece binariamente, a partir de dois elementos, o falo e a castração, ou, ainda, a partir da distinção entre quem tem o falo e quem não o tem: o homem é fálico e a mulher, castrada. O falo é, portanto, elemento central na diferenciação simbólica dos sujeitos.

É interessante observar, porém, que para o autor esse processo de diferenciação da mulher e do homem, articulado à trama edipiana e à castração, é relativamente tardio, pois na infância os dois sexos são tidos como apenas um. De fato, ao diferenciar a organização genital infantil da sexualidade 
adulta, Freud (1905/1996a; 1923/1996d) defende que apenas na segunda, após a puberdade, pode-se falar em polaridade sexual entre masculino e feminino. Antes disso, haveria masculinidade, mas não feminilidade, e a antítese existente seria entre possuir o pênis e ser castrado.

A característica principal dessa 'organização genital infantil' é sua diferença da organização genital final do adulto. Ela consiste no fato de, para ambos os sexos, entrar em consideração apenas um órgão genital, ou seja, o masculino. O que está presente, portanto, não é uma primazia dos órgãos genitais, mas uma primazia do falo. (Freud, 1923/1996d, p. 158)

A centralidade do falo na teoria freudiana também diz respeito ao falo ser a fonte originária da erogenidade corpórea, já que é por sua mediação que tanto o menino como a menina descobrem o prazer autoerótico e se constituem como seres desejantes, não existindo outra possibilidade para isso. Em outras palavras, o falo é condição de possibilidade da estruturação do erotismo, estando as sexualidades masculina e feminina ancoradas nele (Birman, 2001).

Em "Algumas consequências psíquicas da distinção anatômica entre os sexos", de 1924, o psicanalista defende ainda - e essa tese foi alvo de inúmeras críticas - que a diferença entre o desenvolvimento sexual do homem e da mulher, e a ordenação do seu psiquismo são consequência da distinção natural entre seus órgãos genitais, que corresponde à diferença entre uma castração ameaçada e uma castração executada. O próprio título do texto é revelador dessa visão de que o corpo somático impõe a construção do psiquismo no homem e na mulher. E também a passagem a seguir: "Aqui a exigência feminista de direitos iguais para os sexos não nos leva muito longe, pois a distinção morfológica está fadada a encontrar expressão em diferenças de desenvolvimento psíquico. A anatomia é o destino, para variar um dito de Napoleão" (Freud, 1924/1996e, p. 197).

A partir do que foi dito, podemos depreender dois aspectos importantes da problemática da diferença sexual em Freud: masculinidade e feminilidade são entendidos como efeito das diferenças anatômicas entre os sexos, e a primazia do falo sustenta a anterioridade e a superioridade da masculinidade em relação à feminilidade, já que esta seria uma derivação daquela.

A vida sexual feminina, tal como descrita por Freud (1931/1996h; 1933/1996i), é dividida em duas fases, uma masculina e uma feminina. A sexualidade infantil da menina, no que diz respeito às suas manifestações autoeróticas e masturbatórias, teria caráter inteiramente masculino. Seu órgão sexual principal, o clitóris, é, segundo o psicanalista, homólogo à glande do 


\section{ARTIGOS}

pênis. É preciso haver uma onda de recalque na puberdade para que o clitóris ceda lugar à vagina e a masculinidade, à feminilidade.

A criança do sexo feminino, para se tornar mulher, deve então renunciar a determinada soma de atividade, abandonando a masturbação, por exemplo. A entrada da menina no complexo de Édipo é acompanhada por um acentuado abaixamento das pulsões ativas e uma ascensão das passivas, que passam a predominar.

Desse modo, enquanto na puberdade o menino experimenta um grande avanço da libido, conservando a zona erógena dominante da infância, a menina, devido à necessidade de transferência da excitabilidade erógena do clitóris para a vagina, sofre recalques e inibições de sua sexualidade. Cria-se, portanto, uma dissimetria entre as organizações edipianas feminina e masculina e entre as formas de masculinidade e feminilidade na vida sexual adulta. Enquanto a masculinidade reuniria os fatores de sujeito, atividade e posse do pênis, a feminilidade combinaria os de objeto e passividade (Freud, 1923/1996d).

Assim, por sustentar a anterioridade e superioridade da masculinidade em relação à feminilidade, a primazia do falo reforça o pressuposto de hierarquia entre os sexos próprio da tradição do patriarcado. Então podemos afirmar que, além de binária e referida ao falo, a representação freudiana da diferença sexual é ainda hierárquica.

Também a descrição das diferentes reações e possibilidades de destino diante do complexo de castração, no menino e na menina, são reveladores da leitura hierárquica entre os sexos. $\mathrm{O}$ fato de Freud se referir ao pênis como o "órgão sexual correto" (Freud, 1931/1996h, p. 242) e à ausência de pênis na mulher como "inferioridade sexual original" ou "deficiência genital" (Freud, 1931/1996h, p. 131) já é revelador dessa hierarquia.

Além disso, enquanto a reação do menino quando passa a considerar a castração uma ameaça real é o temor, a angústia, a reação que se atribui à menina é a inveja, os sentimentos de injustiça e de vitimização. Essa descoberta da castração e a inveja do pênis que a segue são consideradas pelo psicanalista o marco decisivo da estruturação psíquica da menina, que "deixará marcas indeléveis em seu desenvolvimento e na formação de seu caráter, não sendo superada, sequer nos casos mais favoráveis, sem um extremo dispêndio de energia" (Freud, 1933/1996i, p. 125).

A partir da constatação da castração e, portanto, da diferença sexual, a mulher pode tomar três direções psíquicas no seu desenvolvimento (Freud, 1925/1996g; 1931/1996h; 1933/1996i). A primeira delas é a inibição sexual. 
Ao se descobrir castrada, a menina abandona sua atividade fálica e, com ela, sua sexualidade de modo geral. A segunda é a virilização, isto é, a superenfatização da masculinidade. Por essa via, a mulher se recusa a reconhecer a castração e exagera sua masculinidade prévia e ameaçada. Age como se fosse portadora do falo, evitando a afluência da passividade que abriria caminho à mudança rumo à feminilidade.

A terceira direção é o caminho para a feminilidade "normal", que só se estabelece se o desejo do pênis for substituído pelo desejo de um bebê (Freud, 1933/1996i). Ou seja, a maternidade é a posição subjetiva valorizada por Freud a ser adotada pela mulher para preencher a sua condição de falta (Birman, 2001). Nela há aceitação da condição de castração e tentativa de restauração da completude fálica, a partir de uma equivalência entre o pênis, que ela jamais possuirá, e o filho, que ela de fato poderá ter e por meio do qual ela atingiria a plenitude pela condição de ter o falo.

Para Joel Birman (2001), a maternidade como condição para a feminilidade é a marca maior da moral do patriarcado presente na teoria freudiana, já que ela materializa a máxima de que "a solução para o conflito feminino e o impasse da castração seriam sempre, no discurso freudiano, a restauração da plenitude fálica, por intermédio de algum objeto" (p. 206). Tanto a inibição sexual quanto a virilização são consideradas por Freud como patológicas do ponto de vista libidinal e impeditivas do desenvolvimento da feminilidade da mulher. Nesse sentido, ele reafirma o lugar da mulher no discurso tradicional da dominação masculina.

É importante ressaltar, no entanto, que a teorização freudiana sobre a diferença sexual (marcada por binarismos, hierarquia e centralidade do falo) e o desenvolvimento psíquico do homem e da mulher a partir do complexo de Édipo se mostra atravessada pelo imaginário social do século XIX, mais especificamente pelo paradigma moderno da diferença dos sexos que funda a hierarquia entre os sexos no registro biológico, legitimado pelo discurso da ciência. $\mathrm{Na}$ modernidade os horizontes possíveis para cada sexo passam a ser definidos por marcas inscritas em suas configurações anatômicas (Birman, 2001).

A afirmação freudiana de que "a anatomia é o destino", por exemplo, está coadunada com o pressuposto de que as faculdades psíquicas são efeitos diretos de marcas biológicas. Também a oposição entre masoquismo e passividade de um lado, atribuídos à mulher, e sadismo e atividade de outro, atribuídos ao homem, tem influência desse imaginário marcado tanto pela tradição ética do cristianismo como pela sexologia recém-surgida (Birman, 2001). 


\section{ARTIGOS}

A feminista Gayle Rubin (1975/1998), ao comentar de modo crítico o percurso normativo da feminilidade presente na teoria freudiana, também entende que, quando a menina aceita sua castração e recalca os elementos masculinos da sua libido, sua estrutura libidinal e escolha de objeto entram em congruência com a identidade e os papéis de gênero socialmente atribuídos a ela - uma pequena mulher, feminina, passiva, heterossexual: "nesse esquema, os estereótipos culturais foram cravados sobre uma cartografia dos órgãos genitais" (Rubin, 1975/1998, p. 49; tradução minha).

Sendo assim, não se trata aqui de simplesmente criticar Freud, inclusive porque ele próprio critica em muitos textos, como em "Moral sexual "civilizada' e doença nervosa moderna", de 1908, a modernidade e os malefícios à subjetividade e ao erotismo, sobretudo das mulheres, de uma moral excessivamente repressora das pulsões sexuais. Também a descrição da bissexualidade da histérica feita por ele traz consigo uma denúncia dos limites de um modelo binário de diferença sexual. Além disso, em 1933, em sua conferência sobre a feminilidade, o autor reconhece que os destinos eróticos e sociais da mulher não podem ser pensados sem levar em conta o contexto histórico de sua época:

Talvez seja o caso de que numa mulher, com base na sua participação na função sexual, a preferência pelo comportamento passivo e por fins passivos se estenda à sua vida, em grau maior ou menor, proporcionalmente aos limites, restritos ou amplos, dentro dos quais sua vida sexual serve, assim, de modelo. Devemos, contudo, nos acautelar nesse ponto, para não subestimar a influência dos costumes sociais que, de forma semelhante, compelem as mulheres a uma situação passiva. (Freud, 1933/1996i, p. 116)

Em vez de uma crítica a Freud ou mesmo a Lacan, que veremos a seguir, o que este artigo pretende fazer, com inspiração na metodologia genealógica de Foucault, é criticar como essas teorias, que reforçam certa leitura da diferença sexual em que o falo e a hierarquia entre os sexos são tidos como elementos indispensáveis à subjetivação, são usadas de modo a-histórico na contemporaneidade e acabam servindo para legitimar discursos conservadores e excludentes em relação às diferenças.

$\mathrm{Na}$ teoria lacaniana, é possível observar o prolongamento e o reforço da primazia do falo, já introduzida por Freud, na estruturação subjetiva. Lacan (1956-57/1995; 1957-58/1999a) afirma mesmo que o falo é o eixo de toda a dialética subjetiva, objeto privilegiado na ordem simbólica, e que a primazia do falo já está instaurada no mundo pela existência do símbolo do discurso e da lei. Seriam as próprias particularidades da ordem simbólica que dariam prevalência ao falo e garantiriam sua função constitutiva do sujeito, de 
introduzi-lo em sua posição sexual e de determinar seus destinos sociais, tanto no homem como na mulher.

É isso o surpreendente. É isso que escandaliza aqueles que gostariam que a situação concernente ao objeto sexual fosse simétrica em ambos os sexos. Assim como o homem tem que descobrir e, depois, adaptar a uma série de aventuras o uso de seu instrumento, o mesmo deveria acontecer com a mulher, isto é, que o cunnus ficasse no centro de toda a sua dialética. Mas não é nada disso, e foi precisamente essa a descoberta da análise. (Lacan, 1957-58/1999a, p. 207)

$\mathrm{Na}$ teoria lacaniana, o falo é, portanto, um traço permanente, uma referência universal, cuja presença ou ausência marca as diferenças entre os dois sexos. É, nas palavras do psicanalista lacaniano Joel Dor (1991), "entidade tanto mais irredutível quanto é a unidade significante do real da diferença dos sexos" (p. 18). O falo é também o elemento essencial do declínio do complexo de Édipo, do qual tudo depende. Tanto a masculinidade como a feminilidade se estruturam a partir dele.

Como fica claro, essa centralidade atribuída ao falo como objeto universal e a-histórico, estruturante do psiquismo, já que elemento intrínseco à própria "ordem simbólica", legitima a hierarquia entre os sexos. Na opinião de Rubin, o falo carrega mesmo a significação da dominação do homem sobre a mulher:

Nem a teoria freudiana clássica nem a reformulação lacaniana do processo edipiano teriam sentido se não estivéssemos mais ainda a esse ponto em relações paleolíticas de sexualidade. Continuamos a viver em uma cultura 'fálica'. (...) Nesse sentido, o falo é mais que um traço distinguindo os sexos: ele é a encarnação do estatuto de machos, ao qual os homens acedem e cujos direitos são parte inerente - entre outros, o direito a uma mulher. Ele é uma manifestação da transmissão da dominância masculina. (Rubin, 1975/1998, pp. 44-45)

Também o complexo de Édipo ganha com Lacan a condição de estrutura, na qual o falo e o Nome-do-pai ocupam posições estratégicas (Birman, 2006). Lacan (1956-57/1995; 1957-58/1999a; 1958/1999b) enfatiza a intervenção separadora do pai - que realizaria o corte decisivo da relação do filho com a mãe - e transforma o Édipo em norma de subjetivação e condição de passagem da natureza à cultura.

É importante sublinhar que ao significante Nome-do-pai foi concedida uma condição de exceção na cadeia de significantes, que reafirma a diferença entre os sexos na forma de uma diversidade também entre as funções materna e paterna, e ainda de uma hierarquia entre as condições feminina e masculina: 


\section{ARTIGOS}

"a tese sustentada pelo discurso de Lacan concede fundamento teórico para a lógica, a ética e a política do patriarcado, pela qual a figura do pai, como signo de exceção e representante da Lei, confere uma aura de superioridade hierárquica da figura do homem em relação à da mulher" (Birman, 2006, p. 168).

Podemos então defender que Lacan sustenta uma ontologia da diferença entre os sexos, amparada pelo estruturalismo, ou seja, afirma essa diferença como fundante do humano, atribui à distinção entre masculino e feminino a condição sine qua non da alteridade (Gondar, 2014).

A crítica de Judith Butler à teoria de Lacan incide justamente aí: ela aponta que o psicanalista sustenta as oposições estruturais binárias da antropologia de Lévi-Strauss e a existência de uma ordem simbólica essencialmente imutável, cuja consequência é a criação de dicotomias entre formas de subjetividades normais e desviantes, inteligíveis e ininteligíveis. "Ora, é preciso entender o drama do Simbólico, do desejo, da instituição da diferença sexual, como uma economia significante autônoma que detém o poder de demarcar e excluir o que pode e o que não pode ser pensado nos termos da inteligibilidade cultural" (Butler, 1990/2013, p. 117-118).

Em uma conferência recente em Paris, Butler (apud Lemosof, 2009) disse com humor que poderia aceitar a afirmação lacaniana de que não há relação (rapport) sexual, só relações (relations) sexuais em suplência. Porém, o problema crucial segundo ela, é que apenas algumas suplências são prescritas e valorizadas pela psicanálise, enquanto outras são estigmatizadas. Do mesmo modo ocorre com as identidades de gênero: algumas são afirmadas como primeiras, verdadeiras, legítimas, e outras são vistas como desviantes, falsas, ilegítimas.

Também a psicanalista Sabine Prokhoris (2000), cujas ideias veremos mais à frente, critica que a psicanálise esteja, na atualidade, na posição de fornecer normas ou referências incontestáveis da ordem sexual, ou seja, traçar uma linha de partilha entre os bons e maus modos de ser homem ou mulher, entre figuras adequadas e inadequadas da sexualidade, do feminino e do masculino. Ser bom homem ou boa mulher significa justamente se submeter sem erro à ordem da diferença dos sexos, também chamada de ordem simbólica, e a partir dela constituir "corretamente" seu desejo e sua posição sexual.

A psicanálise reforça, assim, "um inventário de possíveis" do sexo e da diferença sexual, sobretudo por meio de teses sobre ordem simbólica, complexo de Édipo, castração, inveja do pênis na mulher. Em Lacan, a diferença sexual articulada à referência fálica dá acesso à ordem simbólica. Ou se submete a isso ou se precipita no caos do "fora sexo". Disso resultam 
severas chamadas à ordem do "legítimo" e do "humano" nos debates contemporâneos sobre reconfigurações possíveis das normas no campo da sexualidade, e inclusive na clínica.

\section{Novas apostas teóricas}

Vimos até aqui um resumo crítico da leitura da diferença sexual em Freud e em Lacan, que tem o falo, o binarismo e a hierarquia entre o masculino e o feminino em sua base. Como já foi explicitado, o que se considera preocupante e problemático na contemporaneidade é o uso (a-histórico, universalizante) que se faz dessa leitura, uso que conduz a uma interpretação negativa do contemporâneo. Ou, como diz Butler, que cria separações entre subjetividades inteligíveis e subjetividades ininteligíveis, que exclui uma multiplicidade de diferenças do campo da normalidade.

Esse dispositivo diferença sexual, tão presente na psicanálise ainda hoje, restringe a noção de diferença a uma série de oposições sempre binárias, como feminino/masculino, heterossexualidade/homossexualidade, sexo/ gênero, natureza/cultura. As manifestações das sexualidades ficam fixadas a uma lei estabelecida a priori e restritas a apenas duas posições normativas. Cria-se, assim, um "resto" incompreensível e impassível de ser inscrito no âmbito simbólico, impedindo que certas subjetividades, como as transexualidades, possam habitar o mundo viável, legítimo, da sexuação (Arán, 2009).

Diante, seja das críticas feministas e queer à psicanálise, seja das transformações importantes que acontecem hoje no campo da sexualidade e família, alguns autores têm tentado propor novas maneiras de compreender e positivar as subjetividades, inclusive a partir da revisão do conceito de diferença sexual. Veremos a seguir algumas dessas apostas teóricas no sentido do acolhimento das diferenças.

\section{Gozo suplementar}

Há na contemporaneidade uma tentativa de alguns teóricos de responderem, de maneira direta ou indireta, às críticas feitas à psicanálise e a Lacan pelos teóricos feministas e queer. Embora haja pequenas variações em seus argumentos, esses autores se apoiam em conceitos formulados por Lacan nas 


\section{ARTIGOS}

décadas de 1960 e 1970, para defender que eles permitem pensar a sexualidade e a diferença sexual de maneira nova e subversiva. Segundo eles, o grande problema da teoria queer é só levar em conta os conceitos teóricos iniciais de Lacan, anteriores aos anos 1960, como Nome-do-Pai e falo, que no entanto foram recolocados em questão posteriormente pelo próprio Lacan.

No começo da década de 1970, Lacan propõe novos conceitos para pensar a diferença sexual, que culminam com as fórmulas da sexuação a partir das quais ele diferencia o gozo fálico, masculino, do gozo suplementar, feminino, no Seminário 20, Mais, ainda. Segundo o psicanalista, cada sujeito se situa na "posição homem" ou na "posição mulher" da lógica da sexuação, posições que se traduzem por relações diferenciadas de gozo, em articulação com a função fálica. Ele não faz alusão ao sexo anatômico ou à dicotomia entre ter ou não ter falo, e sim a duas modalidades de gozo, o masculino e o feminino (Lacan, 1972-73/2008).

Do lado homem, só há a possibilidade do gozo fálico, um gozo limitado, submetido à ameaça da castração. Já do lado mulher, o gozo é descrito como sem limite, da ordem do infinito. Trata-se de um "gozo dual" (Sáez, 2005): por um lado a mulher está no gozo fálico, já que o falo é referência para os dois sexos, mas, por outro, tem acesso além dele a um gozo suplementar.

Lacan denomina o gozo feminino de suplementar no sentido mesmo de suplemento, de algo a mais, para realçar que ele não é complementar ao gozo fálico. É “um gozo para além do falo” (Lacan, 1972-73/2008, p. 80), não é um gozo que se poderia adicionar ao gozo fálico para formar com ele uma unidade.

$\mathrm{O}$ argumento dos autores contemporâneos quando se apropriam dessa nova construção teórica lacaniana para análise das novas subjetividades e sexualidades é o de que nela o sexo deixa de estar relacionado ao biológico para se atrelar a uma posição discursiva, à lógica da linguagem, possibilitando a cada sujeito se situar em relação à sexualidade na posição homem ou mulher independentemente de ser "macho" ou "fêmea".

No livro Théorie queer et psychanalyse, Javier Sáez (2005) afirma que Lacan, ao propor duas formas de gozo, fálico e suplementar, cria uma teoria da diferença sexual não imaginária e não naturalizada. Não imaginária porque pretende ir além das identificações, relações imaginárias que seriam sempre binárias. Não naturalizada porque admite que um sujeito, independentemente de seu sexo anatômico, pode escolher se inscrever do lado feminino ou masculino do gozo. A diferença sexual não seria aí nem uma essência, nem uma realidade transcendente. Diria respeito a lugares vazios "masculino-feminino" que o sujeito encontra em seu ambiente. 
A topologia lacaniana rompe com esse tipo de binarismo imaginário. Sua capacidade subversiva reside precisamente no fato de que Lacan não teoriza a sexualidade em termos de gênero, mas em termos de gozo. Se um dos principais esforços da teoria queer é pensar a sexualidade fora das categorias de gênero, temos aqui um exemplo disso. (Sáez, 2005, p. 122; tradução minha)

De acordo com essa perspectiva, Lacan seria, portanto, queer antes do tempo, já que pensou a sexualidade fora dos termos do gênero antes do surgimento da teoria queer. Para o psicanalista Fabian Fajnwaks $(2013,2015)$, não há nada de mais queer que o próprio conceito de gozo, sobretudo o de gozo suplementar, fundamentalmente rebelde a toda lei ou universalização.

Fajnwaks (2015), ao comentar uma espécie de lista de gozos sexuais feita por um autor queer — drag queens, drag kings, mulheres de smoking, daddys, butch, homens lésbicos etc. — diz que seria possível reagrupá-los nas duas modalidades de gozo propostos por Lacan. Por um lado, fica claro que esse movimento do psicanalista vai no sentido do acolhimento e da legitimação das múltiplas formas de obtenção de prazer. Por outro, porém, podemos nos questionar se essa categorização das práticas sexuais queer ou na posição "mulher" ou na posição "homem" não implicaria na sua submissão a uma lei e, assim, não limitaria justamente o seu caráter subversivo de desestabilizar e ressignificar a norma?

Desse modo, essa aposta teórica no entendimento da diferença sexual a partir das modalidades de gozo, apesar de certamente avançar no sentido da positivação das diferenças, já que rompe com a anatomia e o gozo suplementar foge à universalização e abarca uma diversidade de experiências possíveis, ainda mantém um sistema classificatório binário, referido ao falo e com presunção de universalidade.

Binário porque mantém a fixidez de apenas duas posições, "homem" e "mulher", restringindo os possíveis da sexuação (David-Ménard, 2009). Referido ao falo porque o falo permanece como origem do erotismo, como referência para as duas posições, mesmo se um gozo está para além dele. Com presunção de universalidade ou ahistoricidade, pois traz consigo a ideia de que as sexualidades de qualquer época ou cultura poderiam ser encaixadas de um lado ou de outro da classificação.

Em outras palavras, essa nova construção teórica acerca das modalidades de gozo acaba sendo tomada pelos autores como estrutura, isto é, como elemento estruturante (universal) das subjetividades. Um indivíduo deverá sempre escolher entre uma das duas posições para se constituir como sujeito e experimentar sua sexualidade. 


\section{ARTIGOS}

A seguir, veremos as propostas de alguns psicanalistas que se diferenciam dos que acabamos de ver por não compartilharem o entendimento da categoria de diferença sexual como estrutura, e sim como dispositivo histórico. E quando se parte da contingência histórica das teorias e das categorias, torna-se possível a sua problematização e transformação.

Se a lei é entendida como uma estrutura anterior à cultura, o simbólico na sua versão diferença sexual é apresentado como uma força que não pode ser modificada sem a ameaça de psicose ou perversão. Se, ao contrário, se parte de Foucault e de Butler, e se entende a lei como algo que é vivido e reiterado nas relações de poder, as subversões não significam necessariamente ameaça à cultura. A própria existência na cultura contemporânea de novas trajetórias subjetivas e formas de construções de gênero produzem deslocamentos e exigem substituições dos modelos ditos normais de sexuação. É preciso então pensar como cada indivíduo, na sua singularidade, vive a diferença (Arán, 2009).

Serão apresentadas apostas teóricas de desconstrução da categoria de diferença sexual e de afirmação de outras possibilidades de diferenciação e experimentação da sexualidade sem a referência necessária ao falo ou a binarismos.

\section{Lógica do limiar}

A psicanalista Jô Gondar (2014) também critica o quadro lacaniano da sexuação, tido por alguns autores como subversivo, como acabamos de analisar, porque as duas posições que ele estabelece, a feminina e a masculina, estão sempre relativas ao falo. Ela compara a sexuação à medida da altura: duas pessoas, uma alta e uma baixa, não se definem assim uma em relação a outra, e sim de acordo com um metro prévio, que permite posicionar a altura e inclusive um além da medida. No caso da sexuação, tanto o gozo fálico como o além do falo são diferenças relativas subordinadas a uma medida prévia, o falo, a partir da qual se definem. A diferença feminina não existiria em si, porque um suplemento está sempre referido a algo do qual é suplemento, a ordem fálica. $\mathrm{O}$ falo seria então a única diferença em si mesma.

A autora entende que as novas formas de experimentar e subjetivar a sexualidade hoje exigem novos modos de se pensar a diferença e a sexuação, que escapem do falocentrismo e da diferença relativa que ainda marcam a teoria psicanalítica. Ela defende que, em vez de instituir a diferença como 
uma posição para além, deve-se fazer o exercício de tornar pensável o que ainda não se diferenciou, o que poderia não estar de nenhum dos dois lados de um quadro da sexuação, o inclassificável.

Os modos de sexuação que se produzem na nossa atualidade social apresentam variações inclassificáveis, segundo o quadro binário de que dispomos na tradição psicanalítica, e indiferenciadas segundo o princípio que faz do falo o diferenciante da diferença. Impõe-se hoje uma multiplicidade de formas sexuais para as quais os estudos queer têm chamado a nossa atenção e que não podemos mais ignorar, ainda que ao preço, certamente, de precisarmos rever nossas balizas teóricas sobre sexualidade. (Gondar, 2014, p. 65)

Essa revisão das balizas teóricas que se torna necessária na atualidade é proposta pela autora a partir da ajuda das noções de limiar, de Walter Benjamin, e de espaço potencial, de Winnicott. Limiar pode ser definido como uma zona de transição, que remete a mudança e fluxo. Não é um limite, porque enquanto este estabelece duas posições e indica um para além (justamente a lógica do quadro lacaniano da sexuação), o limiar implica movimento contínuo, trânsito. Tampouco se confunde com fronteira, pois, ao contrário dela, que separa um domínio e dá ideia de contenção e evitação de transbordamento, o limiar permite ultrapassagens e transições. Indica lugar e tempos intermediários, indeterminados, como a passagem entre o estado de vigília e o adormecer. $\mathrm{O}$ conceito de espaço potencial é próximo ao de limiar, na medida em que também indica um espaço de indeterminação, sem forma acabada, não orientado segundo um objeto ou objetivo.

A abordagem da diferença pela lógica do limiar e do espaço potencial significa, portanto, admitir que as sexualidades e os modos de sexuação são múltiplos e permanentemente "inacabados", são passagens para uma forma que não chega a ser atingida. Sempre seriam possíveis oscilações e transições entre os sexos ao longo de uma vida ou ao longo de gerações.

O espaço potencial se configura como um território de subjetivação e de sexuação sem coordenadas definidas, onde não cabe a ideia de posição sexual. Haveria uma multiplicidade de destinos para o desejo e de modos de se situar em relação ao sexo: espaço do ainda não, em vez de para além. "Ao invés de uma diferença fundada na distinção entre os sexos, teríamos um processo de diferenciação que ainda não encontrou a sua forma. Mas não residiria nesse ainda não a produção da diferença?" (Gondar, 2014, p. 66).

$\mathrm{O}$ ainda não, as formas inacabadas da sexualidade, em transição e oscilação, não significam, no entanto, indiferenciação. Como Gondar afirma nesse trecho, trata-se do contrário disso: é justamente aí que reside a produção 


\section{ARTIGOS}

da diferença, uma diferença não mais referenciada ao falo e ao binarismo sexual. Multiplicidade é muito diferente de indiferenciação, ela possibilita mesmo uma grande variedade de diferenças, heterogeneidades, contingências, encontros.

\section{Vizinhança dos sexos}

Em seu livro Le sexe prescrit: la différence sexuelle en question, Sabine Prokhoris (2000) defende que a diferença dos sexos não existe, é um dispositivo, uma formação do inconsciente, uma construção que nega outros modos possíveis de os indivíduos construírem sua sexuação. Embora pretenda ser a lei, é apenas uma representação, dentre outras possíveis. E se é uma formação do inconsciente, embora muito hegemônica, ela pode ser solucionada ou desfeita, como um sintoma, por exemplo.

A proposta de Prokhoris é que no lugar da diferença dos sexos coloquemos em funcionamento outro dispositivo de sexualidade, o da vizinhança dos sexos, que dissolve e enfraquece as linhas de divisão definitiva entre mulher e homem, e entende o sexual como potência intensiva, perverso-polimorfa, fora de qualquer estruturação prévia pelo dispositivo diferença sexual.

O sexual, capacidade erógena plural, excede, transborda e ultrapassa o sexuado, isto é, a determinação sexuada dos corpos e das identidades. Tem uma aptidão ao transformismo, por identificações, contaminações, contatos. O sexual seria um "originário" aberto a todo tipo de identidade erótica, do qual o sexuado procede, e não o contrário.

[...] não é a sexuação que dita a partição da sexualidade, mas a disposição sexual dita por Freud "perverso-polimorfa", ou seja, absolutamente plástica e apta a todas modulações, que determina as figuras através das quais o sexuado entrará de tal ou tal maneira no dispositivo da sexualidade. (Prokhoris, 2000, p. 178; tradução minha)

Recorrendo ao jogo da vizinhança, com o que ele comporta de deslizamentos e passagens, a autora argumenta que não existem nem o mesmo, nem o outro radical. Só há vizinhos, mais ou menos afastados um do outro. Seguindo essa mesma perspectiva, os novos amores e sexualidades indeterminam o complexo de Édipo e obrigam a tirar novamente as cartas da sexuação. Novos agenciamentos e trajetos podem surgir. 
Nesse dispositivo da vizinhança dos sexos, a análise, em vez de empreender "retificações subjetivas" para colocar o sujeito no bom caminho a percorrer para ser mulher ou homem, deve oferecer um espaço que lhe permita revisar e renovar suas normas de existência, inventar novas lógicas e linguagens para a sua sexualidade.

\section{Feminilidade}

Joel Birman (2001, 2003, 2006, 2011), para dar conta do que surge de novo hoje, sobretudo no campo da sexualidade, desenvolve e positiva o conceito de feminilidade, tal como anunciado por Freud em um de seus últimos textos, "Análise terminável e interminável". Embora esse conceito tenha sido enunciado por Freud de maneira indireta e negativa, como espécie de limite biológico da condição humana, ele nos permitiria ler nas entrelinhas outro ponto de partida para a compreensão do sujeito e para criticar a interpretação da sexualidade como fundada no falo.

Para Birman, o conceito de feminilidade permite reverter a tradição do patriarcado e a centralidade atribuída ao falo predominantes na teoria psicanalítica desde Freud, radicalizadas por Lacan e ainda sustentadas por autores contemporâneos. Apesar de falocêntricas, as teorias de Freud e de Lacan mostram que o inconsciente permeado pelos valores do patriarcado foi historicamente construído. Trata-se na atualidade, então, de desconstruí-lo, retirá-lo de sua a-historicidade pretensamente universalista. O próprio Freud teria indicado o caminho para essa desconstrução, a partir da noção de feminilidade.

Feminilidade em "Análise terminável e interminável" é interpretada por Birman como outro modo de o discurso freudiano se referir à condição desamparada originária do sujeito, de fragilidade e imperfeição. Feminilidade não se identifica com a sexualidade feminina, estaria presente no fundo das modalidades feminina e masculina de ordenação sexual, como algo impossível de se ultrapassar.

A feminilidade estaria, portanto, na origem do psiquismo e do erotismo, seria uma forma de sexo originário, diferente do masculino e do feminino, porque não marcado pelo falo. Ela inverte o modelo ocidental que colocava o masculino como origem. A ordem fálica, posterior, seria uma recusa, um "repúdio à feminilidade" nas palavras de Freud, um horror que o registro do desamparo e da feminilidade produz tanto nos homens como nas mulheres, 


\section{ARTIGOS}

justamente porque nele não se pode mais se proteger com o falo. $\mathrm{O}$ sujeito criaria emblemas fálicos e narcísicos para evitar o reconhecimento de suas finitude e imperfeição, em uma busca desesperada de perfeição e completude.

Pela mediação do conceito de feminilidade, a psicanálise poderia então repensar o erotismo fora do registro fálico que distribui os sexos de modo hierarquizado e naturalizado, e, a partir daí, dialogar com novas demandas, imperativos e formas de subjetivação da contemporaneidade. A feminilidade transcenderia a diferença sexual, por não se identificar nem com a sexualidade feminina nem com a masculina, e criaria novos alicerces para as relações entre os sexos.

Nessa outra leitura de Freud, somos lançados, assim, inequivocamente, na contemporaneidade, na medida em que é necessário superar a aura conferida ao falo como signo da tradição patriarcal, para que possamos adentrar num outro recomeço pós-patriarcal no campo da relação entre os sexos, como nos sugere essa feminilidade originária. Com isso, quem sabe, possamos, homens e mulheres, nos reconciliar com a condição originária da feminilidade, gerando, assim, a ruptura com a hierarquia e a luta de prestígio entre os sexos, anulando, então, a figura da exceção representada pelo Nome-do-Pai. (Birman, 2006, p. 177)

A aposta e a proposta de Birman vão, portanto, na direção da assunção trágica do desamparo e da feminilidade, condição imperfeita e obscura do sujeito, em oposição à perfeição fálica. Aceitar a feminilidade como origem significa se defrontar com outra relação com o falo, agora esvaziado de qualquer marca de perfeição. Significa ainda levar em conta que a condição humana não pode fugir das dimensões erótica e intensiva das pulsões.

O percurso da análise levaria o sujeito a essa experiência de perda da referência fálica e ao encontro com a angústia real que o constitui. Conseguir permanecer nessa posição e suportar a dor que ela provoca, devido à impossibilidade de qualquer referencial fálico, seria um grande desafio, mas também uma abertura a novas possibilidades de subjetivação.

Sob o desamparo, o sujeito se encontra constantemente pressionado pelas forças pulsionais, que o perpassam e inundam. A feminilidade está intimamente ligada a outros dois conceitos freudianos, o de pulsão de morte (Freud, 1920/1996c) e o de masoquismo erógeno (Freud, 1924/1996f). O primeiro indica o mundo das intensidades impossível de ser dominado pelo pensamento ou a vontade, a autonomia da força pulsional em relação ao universo da representação. O segundo diz respeito ao modo de lidar com essas forças pulsionais sem se valer do referencial fálico. Juntos, essas noções mostram que são as intensidades e a afetação que estão na origem. 
Nesse contexto, a sublimação, entendida não como dessexualização ou recalque, mas, ao contrário, como erogenização e criação de novos destinos e tessituras simbólicas para as forças pulsionais e as intensidades ("sublime ação"), seria uma maneira de lidar positivamente com a feminilidade e o desamparo. Trata-se de um a mais de erotização, de possibilidades de mobilidade pulsional. Enquanto polo alteritário, a feminilidade abre novos (des) caminhos para o desejo. A partir dela, o sujeito pode traçar o seu destino singular, pela construção de um "estilo de existência" (Birman, 2011) fundado na experiência trágica da feminilidade e caracterizado pela diferença.

Márcia Arán $(2000,2009)$ também aposta na positivação do conceito de feminilidade como alternativa ao modelo fálico-centrado da diferença sexual na psicanálise, na medida em que pressupõe uma forma de erotismo que, mais do que incluir um gozo além do falo, não tem no falo a sua referência. Retomando as ideias de Birman, a autora defende que a assunção da feminilidade pelo sujeito, experiência de aventura e de risco, conduz a um erotismo não fálico e a um novo exercício da alteridade. Podem surgir então novas e singulares formas de subjetivação e construções de gênero, que não obedeçam a um modelo transcendente, vertical e universal. "É preciso trazer para dentro da teoria a contingência da própria experiência analítica, onde o indeterminado, o singular, o acaso, enfim, o diferente, possam ter lugar" (Arán, 2000, p. 193).

Adotar o ponto de vista feminino-singular, esse gesto de positivação da feminilidade, permite à psicanálise, portanto, reconhecer e acolher novas subjetividades e sexualidades disruptivas, e ainda fazer uma crítica da cultura. A autora entende feminilidade como afirmação de uma multiplicidade de singularidades, a construção de um novo território no qual se possa pensar "diferentemente a diferença".

\section{Considerações finais}

Gozo suplementar, lógica do limiar, vizinhança dos sexos, feminilidade: estas foram as apostas teóricas exploradas neste artigo que respondem à crítica feita à psicanálise pelas teorias feminista e queer e/ou tentam repensar os conceitos da teoria psicanalítica diante das mudanças morais e sociais que marcam o contemporâneo, sobretudo o campo da sexualidade.

$\mathrm{O}$ que se argumentou aqui pode ser resumido da seguinte forma: em primeiro lugar, o entendimento da diferença sexual a partir da oposição gozo fálico (posição homem) e gozo suplementar (posição mulher) permite a 


\section{ARTIGOS}

autores contemporâneos acolherem e positivarem sexualidades que estariam excluídas do campo da inteligibilidade se interpretadas conforme o dispositivo diferença sexual psicanalítico "clássico". Porém, tentou-se mostrar que essa construção teórica, embora avance, tem limitações, porque cria um novo dispositivo, também binário e referido ao falo, e que se impõe como estruturante da experiência subjetiva.

Em segundo lugar, foram descritos novos dispositivos, novas linguagens, não mais da diferença sexual, mas das diferenças, múltiplas. Em comum, lógica do limiar, vizinhança dos sexos e feminilidade argumentam no sentido de que não existe uma ontologia da diferença sexual, ou seja, indicam a historicidade dessa categoria tida como estrutura transcendente, fundante da cultura, necessária para a diferenciação simbólica dos indivíduos e a inteligibilidade de suas experiências e sexualidade.

Trata-se, assim, de novos possíveis para a diferenciação e a subjetivação dos indivíduos, que valorizam sexualidades, identidades, subjetividades atuais que não se encaixam em categorias binárias; de conceitos diferentes que pretendem pensar justamente a diferença sem a necessidade do binarismo, da hierarquia ou da referência ao falo; de dispositivos que se configuram como espaços de análise onde se valoriza o pulsional e se aposta nele como o que possibilita a cada sujeito criar trilhamentos absolutamente singulares.

\section{Referências}

Arán, M. (2000). Feminilidade, entre psicanálise e cultura: o esboço de um conceito. Physis: Revista de Saúde Coletiva, 10(1), 169-195.

Arán, M. (2009). A psicanálise e o dispositivo da diferença sexual. Revista Estudos Feministas, 17(3), 653-673.

Birman, J. (2001). Gramáticas do erotismo: a feminilidade e suas formas de subjetivação em psicanálise. Rio de Janeiro, RJ: Civilização brasileira.

Birman, J. (2003). Fraternidades: destinos e impasses da figura do pai na atualidade. Physis: Revista de Saúde Coletiva, 13(1), 93-114.

Birman, J. (2006). Genealogia do feminino e da paternidade em psicanálise. Natureza Humana, 8(1), 163-180.

Birman, J. (2011). Mal-estar na atualidade: a psicanálise e as novas formas de subjetivação. 8. ed. Rio de Janeiro, RJ: Civilização Brasileira.

Butler, J. (2013). Problemas de gênero: feminismo e subversão de identidade. Rio de Janeiro, RJ: Civilização Brasileira. (Trabalho original publicado em 1990). 
David-Ménard, M. (2009). L'institution des corps vivants selon Judith Butler. In M. David-Ménard (Org.), Sexualités, genres et mélancolie: s'entretenir avec Judith Butler (pp. 197-212). Paris, France: Campagne Première.

Dor, J. (1991). O pai e sua função em psicanálise. Rio de Janeiro, RJ: Zahar.

Fajnwaks, F. (2013). Cultures queer: altérité et homosexualités. In S. Harrison (Org.), Elles ont choisi: les homosexualités féminines (pp. 95-116). Paris, France: Éditions Michèle.

Fajnwaks, F. (2015). Lacan et les théories queer: malentendus et méconnaissances. In F. Fajnwaks, \& C. Leguil (Orgs.), Subversion lacanienne des théories du genre (pp. 19-45). Paris, France: Éditions Michèle.

Foucault, M. (2013). História da sexualidade 1: a vontade de saber. 23. ed. Rio de Janeiro, RJ: Graal. (Trabalho original publicado em 1976).

Freud, S. (1996a). Três ensaios sobre a teoria da sexualidade. In Edição Standard Brasileira das Obras Psicológicas Completas de Sigmund Freud (v. VII, pp. 119-229). Rio de Janeiro, RJ: Imago. (Trabalho original publicado em 1905).

Freud, S. (1996b). Moral sexual 'civilizada' e doença nervosa moderna. In Edição Standard Brasileira das Obras Psicológicas Completas de Sigmund Freud (v. IX , pp. 167-186). Rio de Janeiro, RJ: Imago. (Trabalho original publicado em 1908).

Freud, S. (1996c). Além do princípio da prazer. In Edição Standard Brasileira das Obras Psicológicas Completas de Sigmund Freud (v. XVIII, pp. 17-75). Rio de Janeiro, RJ: Imago. (Trabalho original publicado em 1920).

Freud, S. (1996d). A organização genital infantil: uma interpolação na teoria da sexualidade. In Edição Standard Brasileira das Obras Psicológicas Completas de Sigmund Freud (v. XIX, pp. 155-161). Rio de Janeiro, RJ: Imago. (Trabalho original publicado em 1923).

Freud, S. (1996e). A dissolução do complexo de Édipo. In Edição Standard Brasileira das Obras Psicológicas Completas de Sigmund Freud (v. XIX, pp. 191-199). Rio de Janeiro, RJ: Imago. (Trabalho original publicado em 1924).

Freud, S. (1996f). O problema econômico do masoquismo. In Edição Standard Brasileira das Obras Psicológicas Completas de Sigmund Freud (v. XIX, pp. 175-188). Rio de Janeiro, RJ: Imago. (Trabalho original publicado em 1924).

Freud, S. (1996g). Algumas consequências psíquicas da distinção anatômica entre os sexos. In Edição Standard Brasileira das Obras Psicológicas Completas de Sigmund Freud (v. XIX, pp. 273-286). Rio de Janeiro, RJ: Imago. (Trabalho original publicado em 1925).

Freud, S. (1996h). Sexualidade feminina. In Edição Standard Brasileira das Obras Psicológicas Completas de Sigmund Freud (v. XXI, pp. 233-251). Rio de Janeiro, RJ: Imago. (Trabalho original publicado em 1931). 


\section{ARTIGOS}

Freud, S. (1996i). Novas conferências introdutórias sobre psicanálise: conferência XXXIII - Feminilidade. In Edição Standard Brasileira das Obras Psicológicas Completas de Sigmund Freud (v. XXII, pp. 113-134). Rio de Janeiro, RJ: Imago. (Trabalho original publicado em 1933).

Freud, S. (1996j). Análise terminável e interminável. In Edição Standard Brasileira das Obras Psicológicas Completas de Sigmund Freud (v. XXIII, pp. 225-270). Rio de Janeiro, RJ: Imago. (Trabalho original publicado em 1937).

Gondar, J. (2014). Sexualidades: fronteiras, limites, limiares. Cadernos de Psicanálise - CPRJ, 36(31), 51-68.

Lacan, J. (1995). O seminário. Livro 4. A relação de objeto. Rio de Janeiro, RJ: Zahar. (Trabalho original publicado em 1956-57).

Lacan, J. (1999a). O seminário. Livro 5. As formações do inconsciente. Rio de Janeiro, RJ: Zahar. (Trabalho original publicado em 1957-58).

Lacan, J. (1999b). La signification du phallus. In J. Lacan, Écrits II (pp. 163-174). Paris, France: Seuil. (Trabalho original publicado em 1958).

Lacan, J. (2008). O seminário. Livro 20. Mais, ainda. Rio de Janeiro, RJ: Zahar. (Trabalho original publicado em 1972-73).

Lemosof, A. (2009). Roc de queer. In M. David-Ménard (Org.), Sexualités, genres et mélancolie: s'entretenir avec Judith Butler (pp. 99-122). Paris, France: Campagne Première.

Pombo, M. (2017). Desconstruindo e subvertendo o binarismo sexual e de gênero: apostas feministas e queer. Revista Periódicus, 7(1), 388-404.

Prokhoris, S. (2000). Le sexe prescrit: la différence sexuelle en question. Paris, France: Flammarion.

Rubin, G. (1998). L'économie politique du sexe: transactions sur les femmes et systèmes de sexe/genre. Cahiers du Cedref, 7. (Trabalho original publicado em 1975).

Sáez, J. (2005). Théorie queer et psychanalyse. Paris, France: EPEL.

\section{Resumos}

(Sexual difference, psychoanalysis and contemporaneity: new apparatus and theoretical approaches)

This article aims to review the category of sexual difference in the psychoanalytic theory, considering the critique to psychoanalysis made by feminist and queer theories, and the changes in the field of sexuality, which mark the actuality. Therefore, we explore new theoretical approaches by contemporary authors in order to value 
the differences: supplementary enjoyment (J. Sáez e F. Fajnwaks), threshold logic (J. Gondar), sexes' neighborhood (S. Prokhoris) and femininity (J. Birman e M. Arán).

Key words: Psychoanalysis, sexual difference, contemporaneity, differences

(Différence sexuelle, psychanalyse et contemporanéité: nouveaux dispositifs et essais théoriques)

Cet article prétend réviser la catégorie de différence sexuelle dans la théorie psychanalytique, en considérant la critique des théories féministe et queer à la psychanalyse, et les changements dans le champ de la sexualité qui marquent l'actualité. Pour le faire, on explore des nouveaux essais théoriques d'auteurs contemporains pour valoriser des différences : jouissance supplémentaire (J. Sáez et F. Fajnwaks), logique du seuil (J. Gondar), voisinage des sexes (S. Prokhoris) et féminité (J. Birman e M. Arán).

Mots clés: Psychanalyse, différence sexuelle, contemporanéité, différences

(Diferencia sexual, psicoanálisis y contemporaneidad: nuevos dispositivos y apuestas teóricas)

Este artículo pretende revisar la categoría de diferencia sexual dentro de la teoría psicoanalítica, considerando la crítica de las teorías feminista y queer al psicoanálisis, y los cambios en el campo de la sexualidad que marcan la actualidad. Para dicho fin, se explorarán nuevas apuestas teóricas de autores contemporáneos dirigidas a la valoración de las diferencias: goce suplementario (J. Sáez e F. Fajnwaks), lógica del umbral (J. Gondar), vecindad de los sexos (S. Prokhoris) y femineidad (J. Birman e M. Arán).

Palabras clave: Psicoanálisis, diferencia sexual, contemporaneidad, diferencias

(Geschlechtlicher Unterschied, Psychoanalyse und Gegenwart: neue Instrumente und theoretische Ansätze)

Dieser Artikel versucht, die Kategorie des geschlechtlichen Unterschiedes in der psychoanalytischen Theorie zu revidieren, unter Berücksichtigung der Kritik der feministischen und queer Theorien an die Psychoanalyse und der Veränderungen im Bereich der Sexualität, welche die Gegenwart prägen. Dazu werden neue theoretische Ansätze zeitgenössischer Autoren untersucht, im Sinne einer Positivierung von Unterschieden: ergänzender Genuss (J. Sáez und F. Fajnwaks), Logik der Schwelle (J. Gondar), Nachbarschaft der Geschlechter (S. Prokhoris) und Weiblichkeit (J. Birman und M. Arán).

Schlüsselwörter: Psychoanalyse, Geschlechtlicher Unterschied, Gegenwart, Unterschiede 


\section{ARTIGOS}

Citação/Citation: Pombo M. (2018, setembro). Diferença sexual, psicanálise e contemporaneidade: novos dispositivos e apostas teóricas. Revista Latinoamericana de Psicopatologia Fundamental, 21(3), 543-565. http://dx.doi.org/10.1590/1415-4714.2017v21n3p543.8.

Editores do artigo/Editors: Profa. Dra. Ana Maria Rudge e Profa. Dra. Sonia Leite.

Recebido/Received: 1.6.2018/ 6.1.2018 Aceito/Accepted: 25.7.2018 / 7.25.2018

Copyright: (C) 2009 Associação Universitária de Pesquisa em Psicopatologia Fundamental/ University Association for Research in Fundamental Psychopathology. Este é um artigo de livre acesso, que permite uso irrestrito, distribuição e reprodução em qualquer meio, desde que o autor e a fonte sejam citados / This is an open-access article, which permits unrestricted use, distribution, and reproduction in any medium, provided the original authors and sources are credited.

Financiamento/Funding: Pesquisa financiada com bolsa de doutorado da CAPES (Brasília, DF, Br) e pós-doutorado nota 10 da Faperj - Fundação de Amparo à Pesquisa do Rio de Janeiro (Rio de Janeiro, RJ, Br) / Research funded by CAPES (Brasília, DF, Br) and Faperj - Fundação de Amparo à Pesquisa do Rio de Janeiro (Rio de Janeiro, RJ, Br).

Conflito de interesses/Conflict of interest: A autora declara que não há conflito de interesses / The author has no conflict of interest to declare.

\section{Mariana Pombo}

Psicanalista; Bolsista de Pós-Doutorado Nota 10 da FAPERJ, vinculada ao Programa de Pós-Graduação em Teoria Psicanalítica da Universidade Federal do Rio de Janeiro - UFRJ (Rio de Janeiro, RJ. Br).

marifpombo@gmail.com

This is an open-access article, which permits unrestricted use, distribution, and reproduction in any medium for non-commercial purposes provided the original authors and sources are credited. 